\title{
Tonsillar Undifferentiated Carcinoma
}

National Cancer Institute

\section{Source}

National Cancer Institute. Tonsillar Undifferentiated Carcinoma. NCI Thesaurus. Code C8184.

A non-keratinizing carcinoma arising from the tonsil. It is characterized by the presence of large malignant cells with vesicular nuclei, prominent nucleoli, syncytial growth pattern, and a lymphoplasmacytic infiltrate. 